\title{
Development of High Temperature Multi-Layer Laser Flash Artefacts
}

\author{
Ateeb Farooqui ${ }^{1,3}$ (D) $\cdot$ Roger Morrell $^{1} \cdot$ Jiyu Wu $^{1} \cdot$ Louise Wright $^{1} \cdot$ Bruno Hay $^{2}$. \\ Michael Pekris ${ }^{3} \cdot$ Mark J. Whiting $^{3} \cdot$ Theo Saunders $^{4}$
}

Received: 1 October 2021 / Accepted: 8 October 2021 / Published online: 5 November 2021

(c) The Author(s) 2021

\begin{abstract}
Delamination of the interlayers of multi-layer systems can cause a degradation in functionality, stability and life span of that system. This is even more pertinent for systems at high temperature. Laser flash analysis (LFA) has long been used for thermophysical properties measurements at high temperatures. Multi-layer reference artefacts, with and without, debonded regions are required for validating the thermal characterisation of such systems using LFA. Although some high-temperature bulk candidate reference materials were developed and studied, e.g. in the European Metrology Research Programme (EMRP) funded Joint Research Project (JRP) ENG08 Metrofission, they were not able to meet the requirements for validating thermal measurements of multi-layer systems using LFA. In the European Metrology Programme for Innovation and Research (EMPIR) funded JRP 17IND11 Hi-TRACE project, the National Physical Laboratory is developing multi-layer reference artefacts, including both fully bonded and partially de-bonded systems for validating thermal characterisation of multi-layer systems at temperatures from room temperature to above $1000{ }^{\circ} \mathrm{C}$ using LFA. This paper details the methodology of production, measurement and validation of isotropic graphite and hafnium based multi-layer systems with, and without, partial debonding. Reproducibility, thermal stability and sensitive parameters concerning the thermal response of the artefacts will be discussed, with recommendation on the usage criteria as LFA multi-layer reference artefacts.
\end{abstract}

Keywords Hafnium · Isotropic graphite · Laser flash analysis · Multi-layer systems · Partial de-bonding $\cdot$ Reference artefacts

Ateeb Farooqui

ateeb.farooqui@npl.co.uk

1 National Physical Laboratory (NPL), Hampton Road, Teddington, Middlesex TW11 0LW, UK

2 Laboratoire National de Métrologie et d'essais (LNE), Paris, France

3 University of Surrey, Guildford, Surrey, UK

4 Nanoforce, London, UK 


\section{Introduction}

The laser flash method was first presented by Parker in 1961 [1] as a technique to measure the thermal diffusivity of a solid material. During measurements a specimen is subject to a short high intensity laser pulse on the front face and the temperature response is measured on the rear face. In adiabatic conditions, the thermal diffusivity is then calculated using the time to reach half the maximum temperature. One benefit of LFA is that is can be used to measure the thermal diffusivity at temperatures as high as $3000{ }^{\circ} \mathrm{C}$.

For systems that are required to operate at high temperatures coatings are often employed to protect the substrate material from extreme conditions, creating a multilayer system. Factors such as the thermal resistance of the interface and the presence of a debond or delamination can cause a degradation in functionality, performance and lifespan of the system. A technique that is able to determine the thermal effect of interface resistances and debonding at these temperatures would allow for better design of these critical components, and if used in conjunction with non-destructive debond detection techniques, would allow for users to determine if in-service components require maintenance or have to be replaced.

As the laser flash method is a well-established technique, various studies have been conducted investigating the thermal interface resistance of multilayer systems [2-4]. Some authors have even modelled 2D temperature evolution through the cross section of the specimen [5]. These have all assumed a uniform interface resistance across the full face of the interlayer. The current standard outlining multi-layer systems in LFA is focused on determining properties of one of the component layers (e.g. ISO 18555:2016 [6]), while assuming a perfect bond between the layers.

However, to model a defect such as delamination in the interlayer, a region of increased resistance must be defined. Wright [7] has created a model, tested it and then used it to determine the most sensitive parameters concerning partial delamination in LFA specimens. It was found that interface resistance and area of the debonded region had the largest effect on the transient temperature signal. At present no multi-layer partially debonded reference artefacts are commercially available for laser flash analysis. Such LFA artefacts would allow for the validation of both laser flash equipment and models for measurement of multi-layer systems with variable interface resistances.

This paper presents the details of the methodology of production, measurement and validation of isotropic graphite and hafnium based multi-layer systems both with, and without, partial debonding. The reproducibility, thermal stability and sensitive parameters concerning the thermal response of the multi-layered artefacts are evaluated.

\section{Criteria for Reference Artefacts}

The work conducted in this paper is part of work package 4 of the HI-TRACE project. One of the work package's objectives is the creation of high temperature reproducible and stable multi-layer reference artefacts with and without debonding.

The criteria for making reference artefacts are considered to be: 
1. Stable base materials for the temperature range required; these need to be homogeneous and isotropic, with no phase changes, and ideally infrared opaque;

2. Ability to characterise individually each component material as free-standing materials for density, specific heat and thermal diffusivity;

3. Ability to fabricate a multilayer artefact from dissimilar material components with a defined well-bonded interface of minimal intrinsic thermal resistance;

4. Stability of the multilayer when heated to high temperatures (or conversely when cooled from the fabrication temperature to room temperature) and mechanical integrity, requiring minimal thermal expansion mismatch.

An additional criterion for making reference artefacts with defined defective bonds is the ability to create a defined, reproducible and stable area of weak or no bonding between layers during or after fabrication of the multilayer.

The prospective reference multi-layer artefacts created will also have to demonstrate uniformity between artefacts of the same type and stability over multiple thermal cycles in the LFA thermal transient curve.

\section{Creation of Reference Artefacts}

Various material systems were screened, and the candidate material system, IG-210 grade isotropic graphite with a hafnium foil interface, was selected for detailed characterisation. It was chosen due to its high melting point, the stability of the components, and the ability to easily create reproducible areas of delamination with consistency and uniformity across the metal foil interfaces. Sandstrom [8] has shown that graphite can be fused with metal foils using induction heating, producing strong bonds. In the present case, hafnium foil was chosen for the potential formation of hafnium carbide via diffusion bonding between the graphite discs. This would potentially create an interface bond with a high melting point $\left(3900{ }^{\circ} \mathrm{C}\right)$ [9].

The required dimensions of each layer in a multi-layer artefact for LFA were carefully considered and calculated using the forward model presented by Wright [7]. The IG-210 grade graphite was machined into discs of $12.7 \mathrm{~mm}$ diameter with a surface tolerance of $\pm 5 \mu \mathrm{m}$. The diameter of the disc was chosen to fit the NETZSCH LFA 427 specimen holder at National Physical Laboratory (NPL). The hafnium foil was sandwiched between the graphite discs and then fused using the spark plasma sintering (SPS) process. Four processing temperatures were investigated to create the bond: $1400{ }^{\circ} \mathrm{C}, 1600{ }^{\circ} \mathrm{C}, 1800{ }^{\circ} \mathrm{C}$ and $2000{ }^{\circ} \mathrm{C}$. Following SPS, specimens of each were cross-sectioned and polished. The microstructure and distribution of hafnium and carbon were determined using scanning electron microscope (SEM) imaging and energy-dispersive X-ray spectroscopy (EDS), as shown in Fig. 1. From the SEM secondary electron images in Fig. 1 the transition from hafnium to hafnium carbide can clearly be seen as the processing temperature is increased. Hafnium metal exhibits ductile behaviour and polishes well giving a smooth finish, whereas hafnium carbide, being hard and brittle, tends to fracture and chip when polished, creating a jagged finish. Initially, 
hafnium carbide is only formed at the foil/graphite interface. As the temperature is increased this region of hafnium carbide widens until it spans the entire thickness of the foil. This is further confirmed in the EDS spectra for carbon and hafnium with pure hafnium only being present at lower temperatures and only in the centre of the foil.

The flaking off of the carbide during section preparation could suggest nonuniform grain growth which would leave some areas of hafnium metal within the predominantly hafnium carbide layer. The electron beam interaction volume

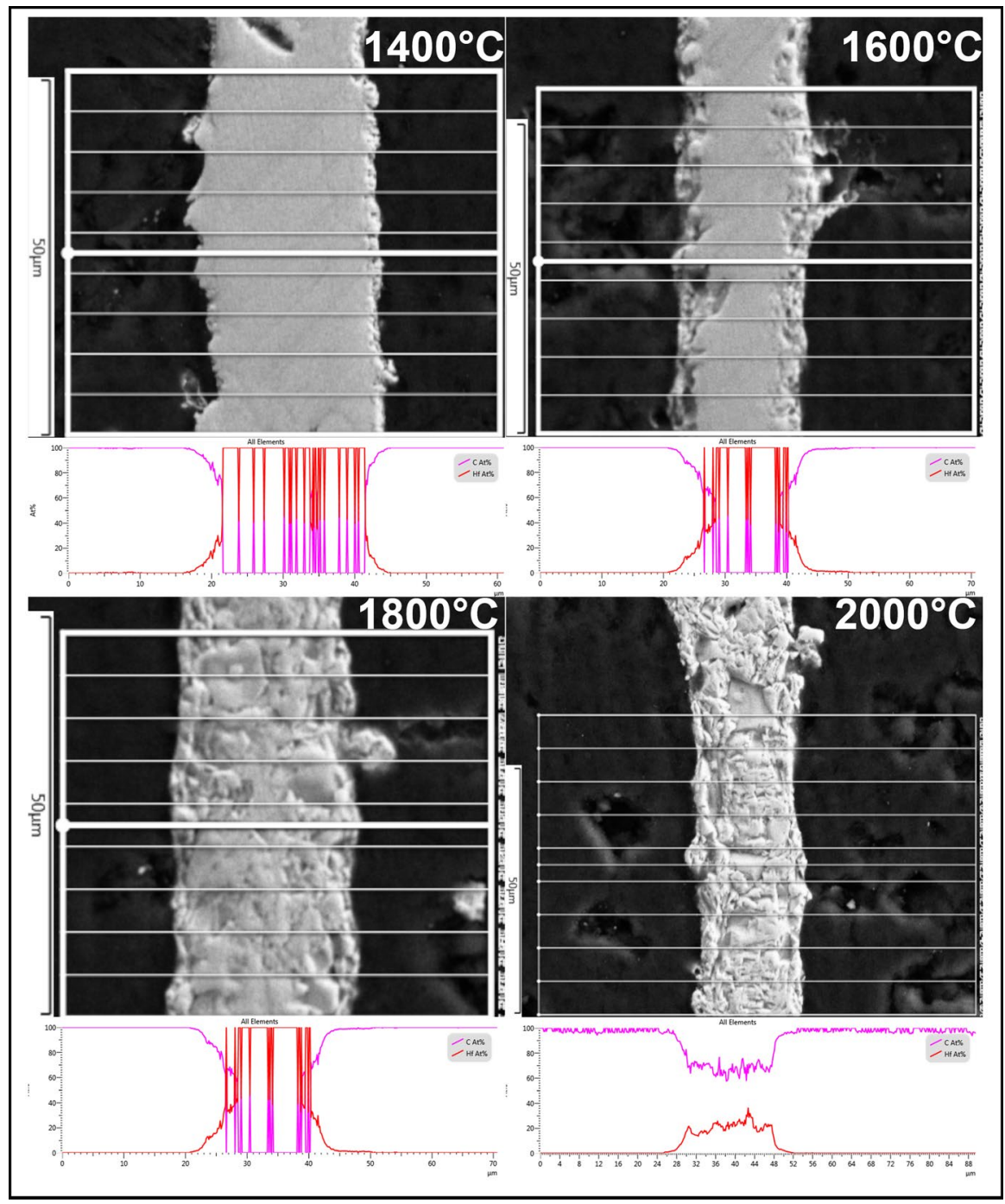

Fig. 1 SEM secondary electron images and 10-line average EDS spectra atomic \% of carbon and hafnium for artefacts bonded at $1400{ }^{\circ} \mathrm{C}$ to $2000^{\circ} \mathrm{C}$ 
during SEM may be picking up these regions, with a 10-line average increasing this chance. These factors explain the noise that is seen in the spectra.

In creating a model 'defective' bond, the defect size needs to be chosen with particular care. If too small, the effect the defect would have on the LFA thermal curve signal would be difficult to distinguish from that of a non-defect artefact. If too large, there is a potential mechanical stability issue, as there would not be enough contact area for the artefact to retain handleability. Defect diameters ranging from $3 \mathrm{~mm}$ to $7 \mathrm{~mm}$ were simulated using the forward model proposed by Wright [7]. It was found that a $6 \mathrm{~mm}$ diameter, $20 \mu \mathrm{m}$ thick air gap defect produced a $132 \%$ increase in the half-rise time when compared to a non-defect artefact, which is well above the uncertainty of the LFA 427 and should easily be distinguishable even if the defect decreases in thickness during formation of the bond.

Hafnium foil of $20 \mu \mathrm{m}$ thickness was cut into discs with an outer diameter of $12.7 \mathrm{~mm}$ using a digital blade cutter. When attempting to create an artefact with a defect, a $6 \mathrm{~mm}$ diameter hole was cut into the hafnium foil disc. When processed at $2000{ }^{\circ} \mathrm{C}$ the defect region would tend to close with the graphite discs deforming under the applied pressure. Therefore, to avoid this, a two-step procedure was developed in which the artefact is heated to $1400{ }^{\circ} \mathrm{C}$ under pressure to form the bond and initiate carbonisation of the hafnium, and then heated to $2000{ }^{\circ} \mathrm{C}$ without pressure to complete the carbonisation while also not closing the defect. An artefact fabricated using this procedure was then imaged in the SEM and can be seen in Fig. 2.

The two-step procedure exhibits the same brittle chipping during polishing as the specimens processed at high temperature (Fig. 1). The EDS spectra also indicates that hafnium carbide present through the thickness of the foil.

Using the established two-step procedure, four different configurations of multi-layer systems were created, each with three examples to give a total 12 artefacts. A schematic of systems with a defect can be seen in Fig. 3.

This system has some unique advantages:

1. High temperature limit (above $2000^{\circ} \mathrm{C}$ ) of both graphite and hafnium carbide interface.

Even though the temperature goal of the work package 4 of the EMPIR 17IND11 Hi-TRACE project is above $1000{ }^{\circ} \mathrm{C}$, the laser flash method has been used above $2000^{\circ} \mathrm{C}$. Therefore, exceeding this goal has the benefit of a reference artefact that can potentially be used at the higher end of the laser flash operational temperature range as well.

2. IG-210 Graphite's thermophysical properties have been characterised in other work packages of the EMPIR 17IND11 Hi-Trace project.

This IG-210 grade graphite batch has been used in an intercomparison between partners in the Hi-Trace project, therefore ensuring the reliability of the thermophysical properties of the components of the systems.

3. Graphite is opaque to laser light.

The laser flash requires the energy from the laser to be absorbed and subsequently heat the specimen. Some materials are semi-transparent to the laser light, 


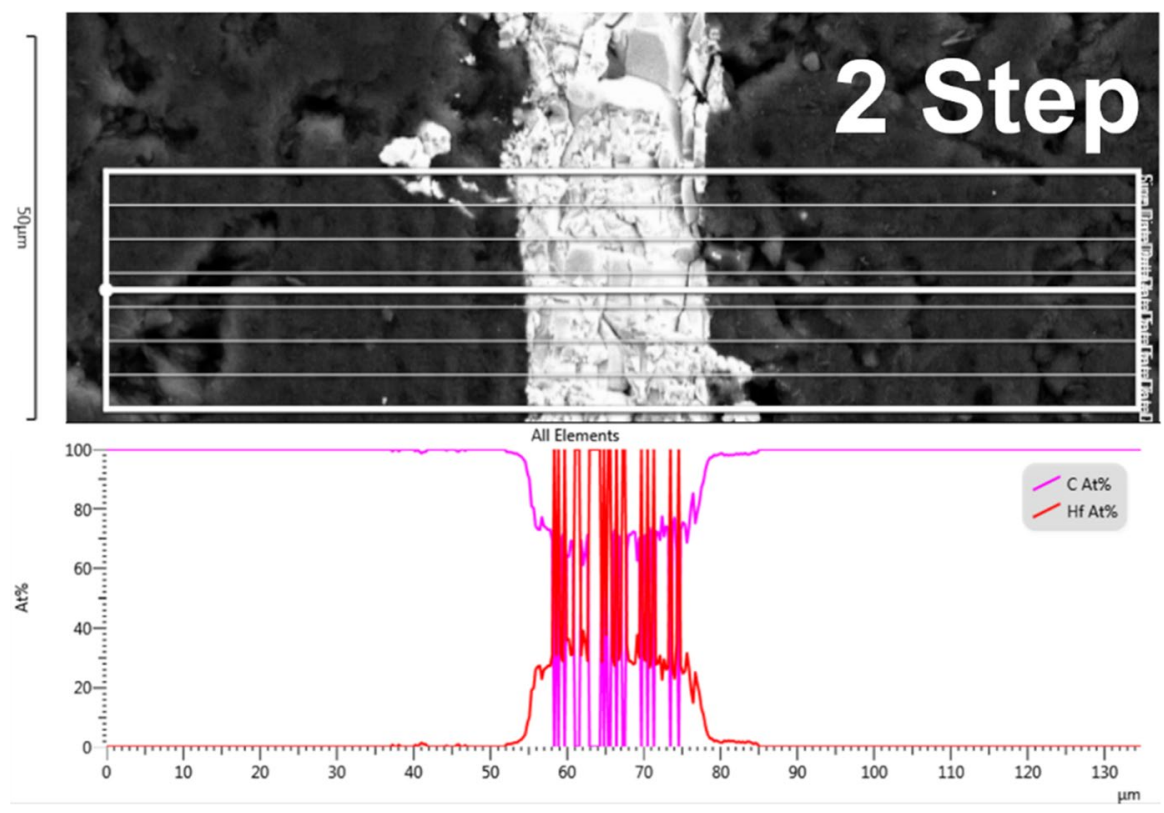

Fig. 2 SEM secondary electron image and 10-line average EDX spectra atomic \% of carbon and hafnium for specimens bonded using a two-step procedure

Fig. 3 Schematic of LFA multilayer partially debonded artefacts. (A) Bi-layer with defect, cross-section view; (B) Tri-layer with defect, cross-section view; (C) Multi-layer debonded specimens, plane view
(A)

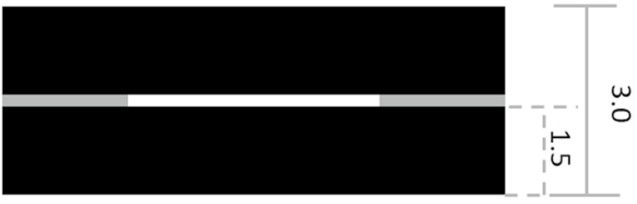

(B)

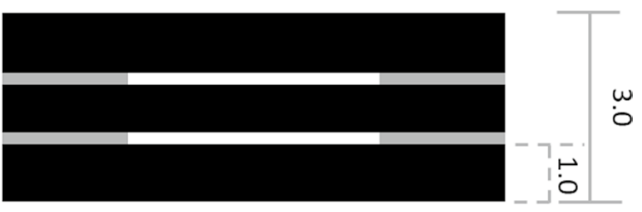

(C)

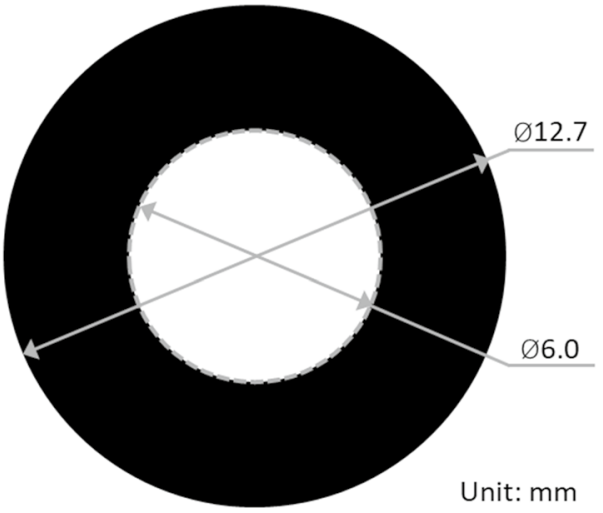


causing some of the light to pass though the specimen straight to the detector changing the measured signal. The commonly used solution is to apply a thin coating of graphite to the surfaces of the specimen to ensure the laser energy is absorbed. For the IG-210 grade graphite, there is no need to apply a layer of thin graphite coating.

\section{Testing Methods}

\subsection{Thermophysical Properties of IG-210 Grade Graphite}

The thermophysical properties of IG-210 grade graphite and measurement methods are shown in Table 1 . The density, specific heat and thermal diffusivity were measured at NPL and the thermal expansion coefficient was measured at the Laboratoire national de métrologie et d'essais, France (LNE). These were then used to calculate the thermal conductivity.

\subsection{Checking Quality of Bond Using Acoustic Scan}

The quality of the bond was checked for each of the 12 manufactured artefacts using a scanning acoustic microscope (SAM) at NPL. During the scan the artefacts must be submerged in water, so they were weighed before and after to detect any water uptake. The artefacts were kept in a laboratory environment for at least $12 \mathrm{~h}$ to allow drying before any further tests.

Table 1 Thermophysical properties of grade IG-210 graphite

\begin{tabular}{|c|c|c|c|c|c|}
\hline \multirow[t]{2}{*}{ Property } & \multirow[t]{2}{*}{ Method } & \multirow[t]{2}{*}{ Uncertainty } & \multicolumn{3}{|c|}{ Temperature $\left({ }^{\circ} \mathrm{C}\right)$} \\
\hline & & & 500 & 700 & 1000 \\
\hline $\begin{array}{l}\text { Thermal conductivity, } \\
\mathrm{W} \cdot \mathrm{m}^{-1} \cdot \mathrm{K}^{-1}\end{array}$ & Calculated & $8 \%$ to $10 \%(k=2)$ & 68.3 & 59.2 & 51.5 \\
\hline Density, $\mathrm{kg} \cdot \mathrm{m}^{-3}$ & Archimedes $^{\mathrm{a}}$ & $0.3 \%(k=2)$ & 1781 & 1775 & 1765 \\
\hline Specific heat, $\mathrm{J} \cdot \mathrm{kg}^{-1} \cdot \mathrm{K}^{-1}$ & $\begin{array}{l}\text { DSC (Setaram, Multievo } \\
\text { 96-line) }\end{array}$ & $6 \%(k=2)$ & 1549 & 1807 & 1892 \\
\hline $\begin{array}{l}\text { Thermal diffusivity, } \\
\mathrm{m}^{2} \cdot \mathrm{s}^{-1}, \times 10^{-6}\end{array}$ & LFA (NETZSCH LFA 427) & $4 \%(k=2)$ & 24.6 & 19.5 & 15.2 \\
\hline $\begin{array}{l}\text { Thermal expansion coefficient, } \\
\text { from } 23^{\circ} \mathrm{C}, \times 10^{-6}\end{array}$ & $\begin{array}{l}\text { Horizontal pushrod dilatom- } \\
\text { eter (NETZSCH DIL402) }\end{array}$ & $10 \%(k=2)$ & 5.0 & 5.2 & 5.5 \\
\hline
\end{tabular}

${ }^{a}$ Determined at room temperature, with data at higher temperatures computed using thermal expansion corrections 


\subsection{Laser Flash Analysis}

The artefacts were measured in the LFA 427 from room temperature up to $1000{ }^{\circ} \mathrm{C}$ at intervals of $100{ }^{\circ} \mathrm{C}$, with laser voltage $450 \mathrm{~V}$ and pulse width $0.8 \mathrm{~ms}$. Measurements were conducted using an argon gas flow rate of $150 \mathrm{ml} \mathrm{s}^{-1}$ and a heating rate of $10{ }^{\circ} \mathrm{C} \cdot \mathrm{min}^{-1}$. The measurement radius on the specimen is automatically set depending on specimen temperature. The measurement radius decreases with the increase of specimen temperature, in order not to saturate the detector.

\subsection{Thermal Cycling to Check Stability}

One artefact from each system was then subject to four additional LFA measurement cycles to thermally cycle the artefact. During each thermal cycle, the artefact was heated to a series of temperature steps at $10{ }^{\circ} \mathrm{C} \cdot \mathrm{min}^{-1}$ and the temperature was maintained within $\pm 3{ }^{\circ} \mathrm{C}$ of the set point at each step until the completion of the measurement before moving onto to next temperature point. The artefacts were measured at the temperature points $18{ }^{\circ} \mathrm{C}, 100{ }^{\circ} \mathrm{C}, 300{ }^{\circ} \mathrm{C}, 500{ }^{\circ} \mathrm{C}, 700{ }^{\circ} \mathrm{C}, 900{ }^{\circ} \mathrm{C}$ and $1000{ }^{\circ} \mathrm{C}$ during the heat up portion and then at the temperature points $800{ }^{\circ} \mathrm{C}$, $600{ }^{\circ} \mathrm{C}, 400{ }^{\circ} \mathrm{C}, 200{ }^{\circ} \mathrm{C}$ and $18{ }^{\circ} \mathrm{C}$ during the cool down portion. Both the LFA thermal transient signals and the dimensional changes were recorded for each thermal cycle. The artefact's thickness was measured at eight locations around the edge and one in the centre using a calibrated Mitutoyo Digital Micrometer IP65. The thickness of the artefact is the average of the measurements at the nine locations, with an estimated standard uncertainty of $\pm 0.008 \mathrm{~mm}$.

\section{Results}

\subsection{Uniformity and Thermal Response}

The SAM images of the interfaces of the artefacts can be seen in Fig. 4 . Row 1 corresponds to the interface of the bi-layer, rows 2 and 3 correspond respectively to the interfaces 1 and 2 of the tri-layer artefact. Generally, the interfaces are consistent for both the bonded and debonded regions. The defect is clearly visible, centred and circular.

Artefact 3LD-2 does show some abnormality in the debonded region of interface 2 , this could be due to some deposition of carbon into the debonded region leading to a transition zone. Artefact 3LD-3 does show some foil missing near the edge of interface 2, but as this is outside the measurement area it is unlikely to affect the measured thermal response; this may however affect its thermal and mechanical stability.

The LFA thermal curves at $1000{ }^{\circ} \mathrm{C}$ for the first thermal cycle (HT1) of each artefact can be seen in Fig. 5 with the half-rise time reported in Table 2. The bi- and tri-layer artefacts without the debond have a very similar response and half-rise time 


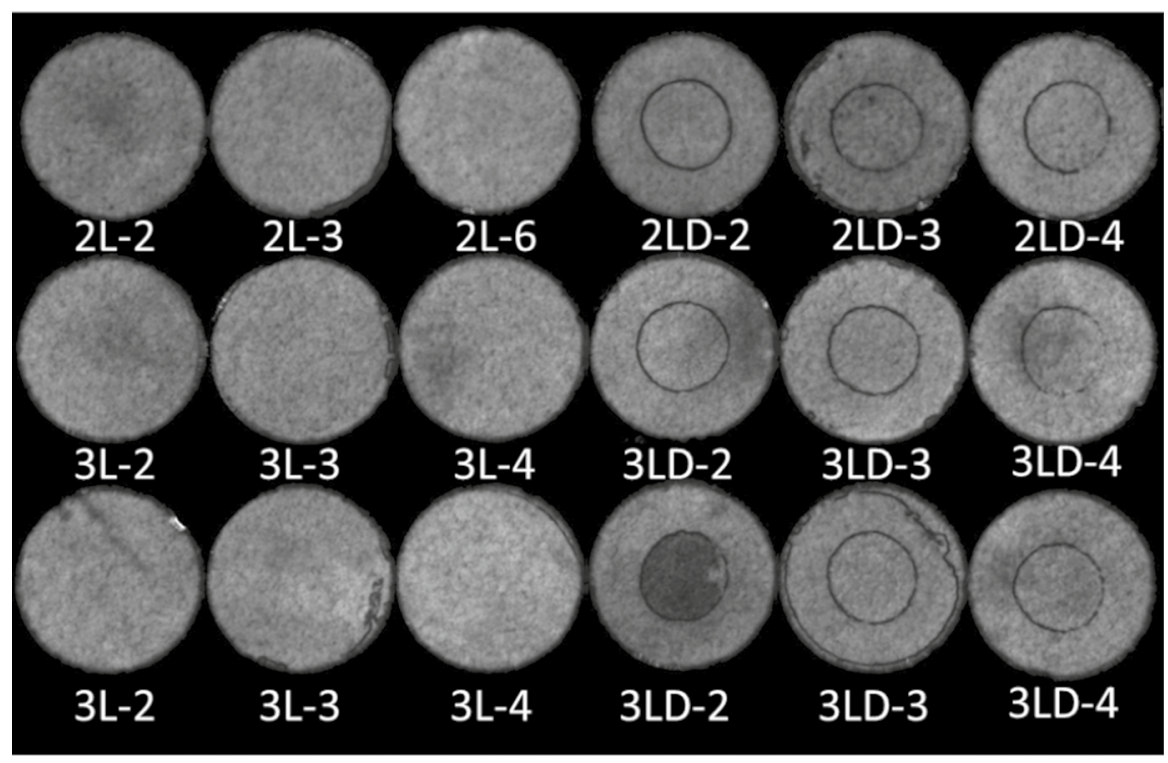

Fig. 4 SAM images of multi-layer graphite LFA artefacts with a hafnium carbide interface. Row 1 corresponds on the interface of bi-layer artefacts. Rows 2 and 3 correspond to interface 1 and 2 of the tri-layer artefacts

to that of a monolayer IG-210 grade graphite with the same thickness of $3 \mathrm{~mm}$, indicating that the hafnium carbide bond provides minimal thermal resistance. The artefacts with the debond show a distinct difference in response from the non-debonded artefacts. The half-rise time of bi-layer artefact with a debond increases by $50 \%$ compared to artefacts without. Tri-layer debonded artefacts have debonded regions in each interface and this shows a larger increase of $~ 85 \%$ in half-rise time.

The artefacts $2 \mathrm{~L}-6,2 \mathrm{LD}-4,3 \mathrm{~L}-4$ and $3 \mathrm{LD}-4$ exhibited a slightly quicker response compared to their counterparts. This was because the discs used were slightly thinner due to extra grinding.

\subsection{Thermal Stability}

The artefacts $2 \mathrm{~L}-6,2 \mathrm{LD}-4$ and $3 \mathrm{LD}-4$ were then measured in the LFA four more times (HT2-HT5). The LFA thermal curves can be seen in Fig. 6. The artefact 3L-4 was thermally cycled only up to HT3 as it exhibited identical behaviour to that of 2L-6. The change in half-rise time for the defect artefacts is presented in Table 3.

From Fig. 6 and Table 3, it can be seen that the LFA thermal curve of 2L-6 does not change significantly up till HT4, at which the thermal response is slowed slightly indicating the start of deterioration of the bond. HT5 then propagates this causing the thermal response to slow further.

From Fig. 6, the artefact 2LD-4 shows small change in the thermal curve up to HT4. However, from Table 3 the half-rise time for HT4 is about $10 \%$ higher than 

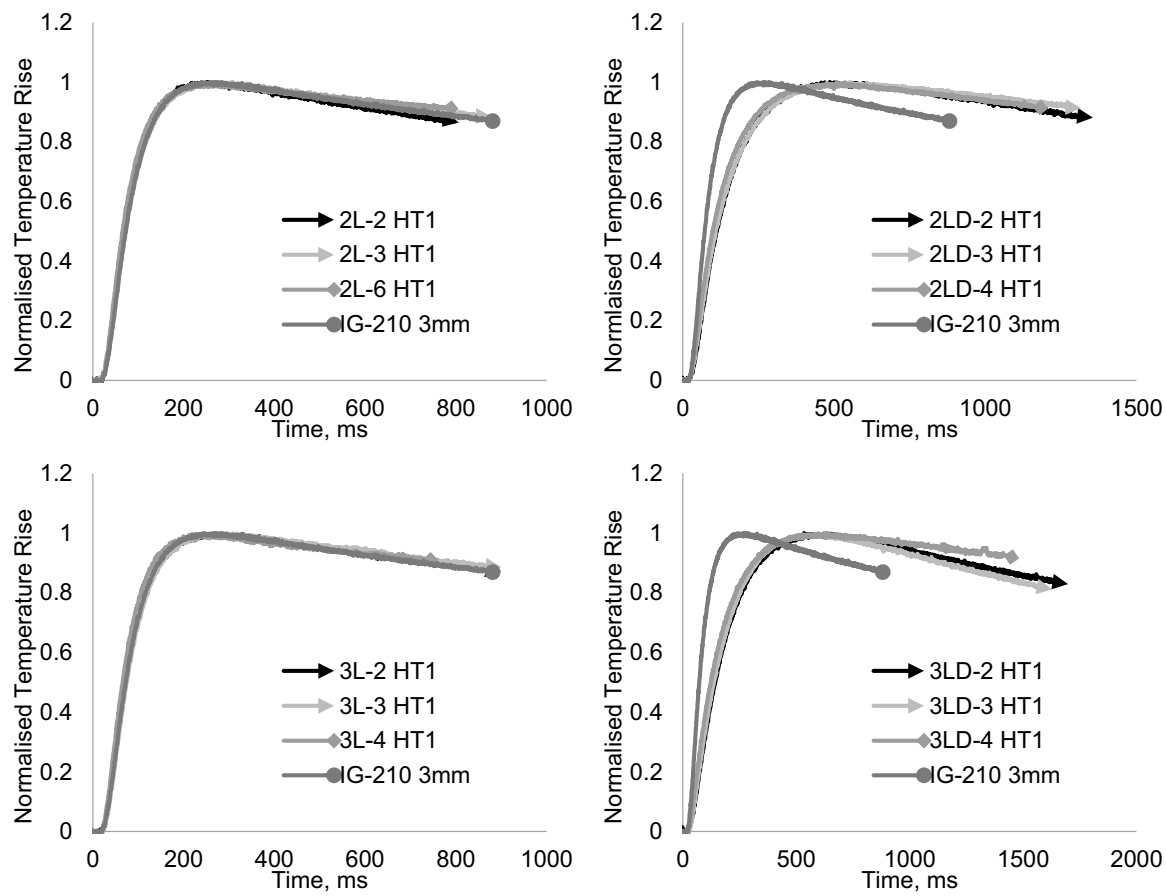

Fig. 5 LFA thermal curves of multi-layer graphite and hafnium carbide artefacts at $1000{ }^{\circ} \mathrm{C}$. Compared to a $3 \mathrm{~mm}$ monolayer of IG-210 grade graphite

Table 2 Half-rise time of multilayer graphite with a hafnium carbide interface LFA artefacts measured at $1000{ }^{\circ} \mathrm{C}$. Includes monolayer IG-210 grade graphite for comparison

\begin{tabular}{lclc}
\hline Artefact ID & $\begin{array}{l}\text { Half-rise time } \\
(\mathrm{ms})\end{array}$ & Artefact ID & $\begin{array}{l}\text { Half-rise } \\
\text { time (ms) }\end{array}$ \\
\hline IG-210 3 mm & 71.7 & & \\
2L-2 & 69.6 & 3L-2 & 72.1 \\
2L-3 & 71.8 & 3L-3 & 73.6 \\
2L-6 & 64.2 & 3L-4 & 64.1 \\
2LD-2 & 110.6 & 3LD-2 & 139.8 \\
2LD-3 & 108.3 & 3LD-3 & 134.1 \\
2LD-4 & 96.5 & 3LD-4 & 120.2 \\
\hline
\end{tabular}

that of HT1 at $1000{ }^{\circ} \mathrm{C}$. The thermal curve of HT5 shows substantial delay and the half-rise time is more than doubled at $1000{ }^{\circ} \mathrm{C}$.

The average thickness follows a similar trend, negligible change for the first three thermal cycles, slight change of $+6 \mu \mathrm{m}$ at HT4 and then a substantial change of $+25 \mu \mathrm{m}$ at HT5. This increase in thickness would not normally cause such large increases in half-rise time. This indicates that the artefact most likely starts to delaminate during HT4 which then accelerates during HT5. This could be caused by the defect region becoming more severe (thicker) or further delamination in the bonded regions. Both would increase the interface resistance of that respective region, 

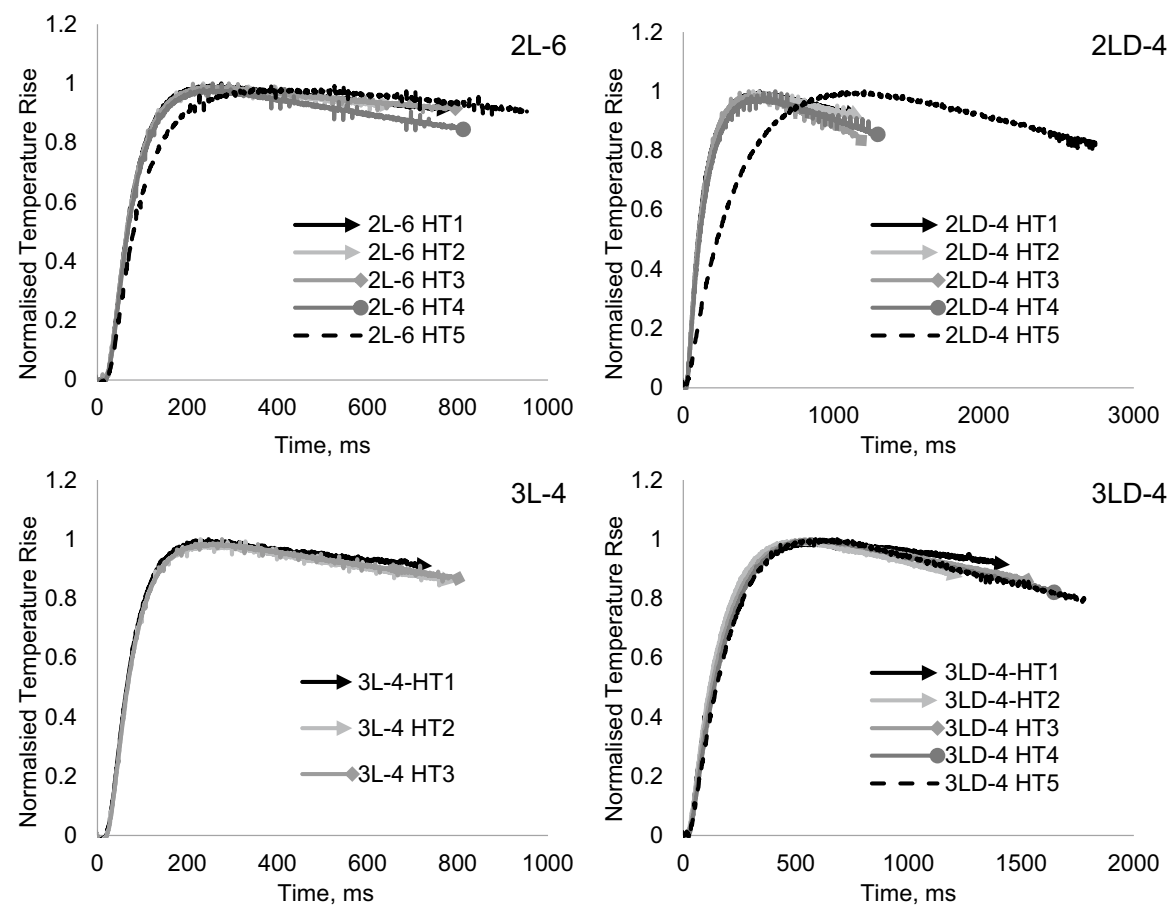

Fig. 6 LFA thermal curves of graphite hafnium artefacts $2 \mathrm{~L}-6,2 \mathrm{LD}-4,3 \mathrm{~L}-4$ and $3 \mathrm{LD}-4$ at $1000{ }^{\circ} \mathrm{C}$, after the 1st, 2nd, 3rd, 4th and 5th thermal cycle

leading to a slower response. Because $2 \mathrm{~L}-6$ displays the same change in signal as the defect systems, it likely points to the bonded region to be area of deterioration.

The artefact 3LD-4 seems to stay relatively stable up until HT3 at room temperature. Above room temperature there is a slight slowing in the thermal curve and half-rise time. It continues to slow with increasing number of thermal cycles, but at a steadier rate when compared to $2 \mathrm{LD}-4$, ending at $28.1 \%$ and $23.4 \%$ increases in half-rise time from HT1 to HT5 at room temperature and at $1000{ }^{\circ} \mathrm{C}$ respectively. The thickness follows this trend increasing steadily though the thermal cycles.

The thermal stability characterisation has shown that all artefacts proved to be thermally and mechanically stable for the first two to three thermal cycles. Albeit not ideal, this is thought to be sufficient for use in intercomparison, in which only two full measurement cycles will be conducted.

\section{Discussion}

\subsection{Difference in Cooldown between 2 and 2LD Artefacts}

The thermal curves of $2 \mathrm{~L}-2$ and $2 \mathrm{LD}-2$ show that $2 \mathrm{LD}-2$ has a slower cooldown from the peak temperature rise. As the measurement radius is only $0.6 \mathrm{~mm}$, it is 
Table 3 Half-rise time for the artefacts $2 \mathrm{~L}-6,2 \mathrm{LD}-4,3 \mathrm{~L}-4$ and $3 \mathrm{LD}-4$ at room temperature, $500{ }^{\circ} \mathrm{C}$, $700{ }^{\circ} \mathrm{C}$ and $1000{ }^{\circ} \mathrm{C}$ and average thickness after 1 st, $2 \mathrm{nd}, 3 \mathrm{rd}, 4$ th, and 5 th thermal cycles

\begin{tabular}{|c|c|c|c|c|c|}
\hline \multirow[t]{2}{*}{ Heat cycle } & \multirow[t]{2}{*}{ Thickness (mm) } & \multicolumn{4}{|c|}{ Half-rise time (ms) } \\
\hline & & $18^{\circ} \mathrm{C}$ & $500{ }^{\circ} \mathrm{C}$ & $700{ }^{\circ} \mathrm{C}$ & $1000^{\circ} \mathrm{C}$ \\
\hline \multicolumn{6}{|l|}{$2 \mathrm{~L}-6$} \\
\hline HTO & 2.755 & & & & \\
\hline HT1 & 2.754 & 12.9 & 41.4 & 51.6 & 64.2 \\
\hline HT2 & 2.756 & 13.0 & 41.6 & 51.6 & 64.3 \\
\hline HT3 & 2.756 & 13.1 & 41.7 & 52.0 & 64.6 \\
\hline HT4 & 2.758 & 12.9 & 41.8 & 52.5 & 65.8 \\
\hline HT5 & 2.764 & 15.7 & 48.5 & 63.0 & 78.0 \\
\hline \multicolumn{6}{|l|}{ 2LD-4 } \\
\hline HT0 & 2.730 & & & & \\
\hline HT1 & 2.729 & 21.4 & 65.7 & 79.6 & 96.5 \\
\hline HT2 & 2.731 & 22.1 & 68.7 & 82.5 & 99.0 \\
\hline HT3 & 2.731 & 22.8 & 67.3 & 81.1 & 96.7 \\
\hline HT4 & 2.736 & 23.2 & 69.0 & 86.4 & 105.9 \\
\hline HT5 & 2.755 & 36.8 & 104.9 & 154.5 & 229.3 \\
\hline \multirow[t]{2}{*}{ Heat cycle } & Thickness (mm) & \multicolumn{4}{|c|}{ Half-rise time (ms) } \\
\hline & & $17^{\circ} \mathrm{C}$ & $500^{\circ} \mathrm{C}$ & $700{ }^{\circ} \mathrm{C}$ & $1000^{\circ} \mathrm{C}$ \\
\hline \multicolumn{6}{|l|}{$3 \mathrm{~L}-4$} \\
\hline HT0 & 2.745 & & & & \\
\hline HT1 & 2.745 & 13.9 & 42.0 & 51.8 & 64.1 \\
\hline HT2 & 2.744 & 13.8 & 42.4 & 52.3 & 64.8 \\
\hline HT3 & 2.744 & 14.1 & 43.0 & 53.0 & 65.3 \\
\hline \multicolumn{6}{|l|}{ 3LD-4 } \\
\hline HT0 & 2.744 & & & & \\
\hline HT1 & 2.743 & 27.9 & 82.3 & 99.5 & 119.2 \\
\hline HT2 & 2.746 & 26.5 & 81.9 & 97.6 & 115.2 \\
\hline HT3 & 2.745 & 26.6 & 86.1 & 105.3 & 125.7 \\
\hline HT4 & 2.747 & 31.3 & 92.7 & 115.3 & 135.9 \\
\hline HT5 & 2.750 & 35.7 & 103.4 & 126.5 & 147.1 \\
\hline
\end{tabular}

fully encompassed by the defect. When the heat pulse travels though the artefact, a large portion bypasses the defect and is not picked up by the detector, leading to portions of the artefact already being past their peak temperature rise while the measurement region is still to reach its peak. This would then give the effect of a slower cooldown as the measurement region would not rise to as high a temperature and thus would cooldown slower after its peak. 


\subsection{Deterioration of Artefacts with Thermal Cycling}

After the artefacts were measured for the third or fourth time, they began to slow a little in their thermal response. As this occurs in artefacts both with and without defects it is likely that there is deterioration in the hafnium carbide bonded region. Possible explanations include:

- Figure 2 indicates that the grain size of the hafnium carbide varies, and some voids are present. It is possible that this microstructure arises because of nonuniform diffusion of carbon into the hafnium during the spark plasma sintering process. The deterioration is likely not an artefact of sectioning and polishing. Local variation in diffusion may lead uneven conversion of hafnium to hafnium carbide leading to larger grains and voids which facilitate interface crack propagation as they produce an intrinsically weaker interface.

- The joined artefacts are created under load. This could lead to residual stresses in the artefact, which as they are thermally cycled begin to relax, stressing and cracking the interface and leading to a deterioration of the thermal response.

- The graphite itself may not be mechanically stable enough during thermal cycling (see, for example Cosculluela [10]). A small amount of thermal expansion hysteresis and dimensional 'ratchetting' may be developed which affects the stability of the hafnium carbide interface.

- The coefficient of thermal expansion of IG-210 grade graphite is $5.5 \times 10^{-6} \mathrm{~K}^{-1}$ $\left(25-1000{ }^{\circ} \mathrm{C}\right)$, while hafnium carbide is generally reported to have a value a slightly different. Grisaffe [11] reports a value of $6.6 \times 10^{-6} \mathrm{~K}^{-1}\left(25-612{ }^{\circ} \mathrm{C}\right)$ while Neel [12] reports $5.0 \times 10^{-6} \mathrm{~K}^{-1}\left(21-1018^{\circ} \mathrm{C}\right)$. While these are close, any mismatch would potentially create stresses at the interface due to the two layers expanding and contracting by differing amounts when heated and cooled respectively. This stress may be great enough over time to initiate cracking.

\section{Conclusions and Future Work}

High-temperature multi-layer LFA artefacts with and without defined debonds were created and characterised. The production of the artefacts was shown to be reproducible, with the defect regions being consistent, circular and centred. The LFA thermal curves were consistent between artefacts of the same type, indicating good uniformity among the artefacts. The thermal stability was also investigated, and all artefacts were shown to be stable for at least two to three thermal cycles, which is considered to be sufficient for use in the intercomparisons in the Work Package 4 of the Hi-Trace project.

In future work, the data collected from the artefacts will be used in a finite volume inverse model [13] to determine the thermal interface resistance of the bonded and debonded regions. Scanning electron microscopy will be used to analyse the change in the microstructure of the interface, the dimension of the defected region, and the composition near the interface with increasing thermal cycles. From this, 
improvements will be made to the artefact design or manufacturing process to increase the thermal stability.

Acknowledgements This study was performed as part of the EMPIR 17IND11 Hi-TRACE project which has received funding from the EMPIR programme co-financed by the Participating States and from the European Union's Horizon 2020 research and innovation programme. This study was also supported by the EPSRC's Centre for Doctoral Training at the University of Surrey. The authors also thank other colleagues at NPL, Helen Jones, Maria Lodeiro, Petra Mildeova and Tony Fry for their contributions and feedbacks to the work presented in this paper.

Authors Contributions Conceptualization: [AF, RM, JW]; model creation: [LW]; sample preparation: [AF]; sample creation: [TS]; formal analysis and investigation: [AF, RM, JW]; writing-original draft preparation: $[\mathrm{AF}]$; writing — review and editing: [AF, RM, JW, LW, BH, MP, MW, TS]; funding acquisition: [BH, JW]; supervision: [JW, RM, MP, MW].

Data Availability All data generated or analysed during this study are included in this published article.

\section{Declarations}

Conflict of interest The authors declare that they have no conflict of interest.

Ethical Approval Not applicable.

Open Access This article is licensed under a Creative Commons Attribution 4.0 International License, which permits use, sharing, adaptation, distribution and reproduction in any medium or format, as long as you give appropriate credit to the original author(s) and the source, provide a link to the Creative Commons licence, and indicate if changes were made. The images or other third party material in this article are included in the article's Creative Commons licence, unless indicated otherwise in a credit line to the material. If material is not included in the article's Creative Commons licence and your intended use is not permitted by statutory regulation or exceeds the permitted use, you will need to obtain permission directly from the copyright holder. To view a copy of this licence, visit http://creativecommons.org/licen ses/by/4.0/.

\section{References}

1. W.J. Parker, R.J. Jenkins, C.P. Butler, G.L. Abbott, J. Appl. Phys. 32, 1679 (1961)

2. H.J. Lee, R.E. Taylor, J. Appl. Phys. 47, 148 (1976)

3. J. Hartmann, O. Nilsson, J. Fricke, High Temp. High Press. 25, 403 (1993)

4. C.-P. Chiu, J. Maveety, L. Varner, in Internantional Symp. Microelectron. (2000)

5. N.D. Milošević, M. Raynaud, Int. J. Heat Mass Transf. 47, 1627 (2004)

6. International Organization for Standardization, Metallic and Other Inorganic Coatings-Determination of Thermal Conductivity of Thermal Barrier Coatings (ISO 18555:2016) (2021)

7. L. Wright, A. Farooqui, J. Wu, R. Morrell, M. Pekris, and M. Whiting, in 34th Int. Therm. Conduct. Conf. Int. Therm. Expans. Symp. (DEStech Publications Inc, Wilmington, Delaware, 2019), pp. 3-12

8. D. Sandstrom, Joining Graphite to Graphite with Transition Metal Foils Lab Report LA-3960 (Los Alamos, 1968)

9. H. Bittermann, P. Rogl, J. Phase Equilibria 18, 344 (1997)

10. A. Cosculluela, J. Farre, J. Phys. IV JP 7, C3-471-C3-476 (1997)

11. S.J. Grisaffe, J. Am. Ceram. Soc. 43, 495 (1960)

12. D. S. Neel and C. D. Pears, The Thermal Properties of Thirteen Solid Materials To 5000F For Their Destruction Temperatures. (Birmingham, Alabama, 1962). 
13. L. Wright, J. Wu, and A. Farooqui, in 14th World Congr. Comput. Mech. ECCOMAS Congr. (Paris, France, 2020).

Publisher's Note Springer Nature remains neutral with regard to jurisdictional claims in published maps and institutional affiliations. 